J. Linguistics 4I (2005), 269-305. (C) 2005 Cambridge University Press

doi:I0.IOI7/S0022226705003270 Printed in the United Kingdom

\title{
A multi-dimensional approach to the category 'verb' in Cantonese ${ }^{1}$
}

\author{
ELAINE J. FRANCIS \\ Purdue University \\ STEPHEN MATTHEWS \\ University of Hong Kong
}

(Received I8 August 2003; revised I9 December 2004)

\begin{abstract}
Cantonese exhibits a pattern of variation among verbs that has often been interpreted as distinguishing a category of adjectives or a subcategory of adjectival verbs. However, neither of these approaches takes into account the complex patterns of overlap among the purported categories or subcategories. To account for these patterns, we propose a multi-dimensional, feature-based analysis, whereby morphological, phonological, syntactic, and semantic features interact to determine the distribution of each verb. While all verbs bear the same syntactic category feature, there are other features that affect the distribution of verbs independently of syntactic category. For example, constructions that resemble adjectival constructions in other languages license the semantic classes of verbs that are permanent, gradable, and/or non-dynamic, while constructions that resemble verbal constructions in other languages license the semantic classes of verbs that are dynamic, non-gradable, and/or non-permanent. Typological implications of this analysis are also considered.
\end{abstract}

\section{VARIATION AND LEXICAL CATEGORIES: TWO PROBLEMS}

All current theories of syntax assume some notion of lexical category in recognition of the distinctive grammatical behaviour of different classes of words. Since Chomsky (1970), the dominant position in formal linguistics has been that the assignment of a word to a category is a matter of specifying a particular set of syntactic features in its lexical entry, as in the system of Chomsky (I98I), which cross-classifies the categories noun, verb, adjective, and preposition using the universal, binary features $[ \pm N]$ and $[ \pm V]$. Thus,

[I] We gratefully acknowledge Nik Gisborne, David Kemmerer, Robert D. Borsley, two anonymous $J L$ referees, and two other anonymous referees for their constructive comments on earlier versions of this paper. We would also like to thank Winnie Yiu, Richard Wong, and Virginia Yip for their assistance with the Cantonese data. Our research was funded in part by a Research Initiation Grant awarded in September 2000 to Elaine J. Francis by the University Research Committee of the University of Hong Kong. 
nouns are specified for the syntactic features $[+\mathrm{N}-\mathrm{V}]$, while verbs are specified for the opposite features, $[-\mathrm{N}+\mathrm{V}]$. Such a feature system leaves a number of issues to be addressed, including two general problems raised in Francis (1999). The first involves cross-linguistic variation (Anward, Moravcsik \& Stassen 1997, Vogel \& Comrie 2000): if nouns in all languages are specified for the features $[+\mathrm{N}-\mathrm{V}]$, then what exactly is the common core of syntactic behaviour that can be identified among the nouns of different languages? Furthermore, if the feature system is universal, then why do the inventories of categories appear to differ from language to language? For example, in some languages the category of 'adjective' is a small closed class, while in others it is an open class (Dixon 1977). For languages such as Lushootseed and Cora (Beck 1999) and Thai (Prasithrathsint 2000), there appears to be no category of adjectives at all distinct from verbs.

The second problem involves variation among members of a category within a single language. For example, while English clearly distinguishes a category of adjectives, there is a great deal of variation among its members: some allow comparison with -er (few/fewer), some do not (absent $/ *$ absenter). Some adjectives (main) occur only in attributive position, others (asleep) only in predicate position (Bolinger 1967). If all adjectives bear the same category features, what grammatical properties (if any) do they have in common, and what accounts for the distributional differences among them?

These two problems have prompted a number of alternative approaches to lexical categories. Functional-typological theories invoke semantically or pragmatically grounded 'prototypes' to account for within-category variation, and implicational hierarchies of various sorts (some of which also refer to prototypes) to account for cross-linguistic variation in category systems (Hopper \& Thompson 1984; Croft I99I, 200I; Hengeveld I992; Wetzer 1996; Stassen 1997; Beck 1999). For example, Croft (I99I, 200I) defines the prototype for the category 'noun' cross-linguistically as a correlation of the semantic class of physical objects with the pragmatic function of reference. Within a given language, some nouns (e.g. those used as modifiers or predicates) may fail to conform to the prototype, and such nouns are predicted to display defective or marked grammatical behaviour relative to prototypical nouns. While most of the nouns in a language share at least some grammatical properties with prototypical nouns, it is NOT assumed that all nouns bear the same syntactic features, either within a language or across languages. Rather, the patterns of variation and markedness within each category, as well as the cross-linguistic similarities among category systems, are attributed to universal semantic-pragmatic prototypes.

Alternative (non-Chomskian) generative approaches also invoke functional explanations for the marked or defective behaviour of some category members (McCawley 1982, Sadock 1990, Bresnan 1995, Yuasa 1998, Culicover 1999, Francis 1999, Malouf 2000, Yuasa \& Francis 2003). Rather than invoking prototypes, however, these theories assume some variant of 
Chomsky's syntactic feature system to represent syntactic category information. 'Parallel-architecture' theories accommodate variation within categories by means of additional, independent features specified at distinct but parallel levels of grammatical structure, including syntax, semantics, and morphology. To the extent that the associations of morphological, syntactic, and semantic features vary, items belonging to the same syntactic category may display different grammatical patterns. For example, quantificational nouns such as lot in a lot of people bear the morphological and syntactic features of (count) nouns, but semantic features that are otherwise typical of quantifiers, resulting in unusual patterns of agreement and distribution that contribute to grammatical variation among English nouns (Yuasa \& Francis 2003). The problem of cross-linguistic variation has received less attention from parallel-architecture theories and, as with Chomskian theories, it is not clear how the syntactic features associated with lexical categories can accommodate cross-linguistic differences in category systems.

Within the Chomskian tradition itself there has been relatively little discussion of these problems. However, Newmeyer (1998: I65-208) argues that if we assume a modular grammatical architecture in which semantic or pragmatic factors may affect syntactic distribution independently of syntactic category information (essentially, an approach similar to that of the parallel-architecture theories), then the functionalist idea of 'prototype' is not necessary to account for within-category variation. Baker (2003) focuses on within-category similarity, arguing that the lexical categories 'noun', 'verb', and 'adjective' can be given substantive syntactic definitions that apply to all category members in all languages, even those for which a distinct category of 'adjective' is not immediately apparent.

In this paper, we investigate the category 'verb' in Cantonese against the theoretical landscape outlined above, addressing both the problem of crosslinguistic variation in category systems, and that of grammatical variation within a particular category of a language. Cantonese exhibits a pattern of variation within the category 'verb' that appears to be distinctive of languages lacking a large open class of adjectives as distinct from verbs. In previous studies of Cantonese and Mandarin, this variation has been described in terms of either traditional verbal subcategories (Li \& Thompson 198I; Matthews \& Yip I994) or distinct categories of verb and adjective (Paul 2003). In section 2, we show that neither of these traditional approaches is adequate to explain the patterns of distribution seen in our data.

In section 3, we introduce a parallel-architecture theoretical approach to the problem of variation within lexical categories, framed within Autolexical Grammar and based on Sadock (I990, I99I, 2003) and Francis (1999). Our approach also incorporates insights from Croft's (200I) Radical Construction Grammar. We then show how this approach can account for the Cantonese data introduced in section 2. We propose that the syntactic categories of a (configurational) language are characterized at the level of syntax 
by particular phrase-structure configurations, and by prototypical correspondences with certain semantic and morphological categories (McCawley 1982; Sadock I99I, 2003). Distinct from these purely syntactic categories are construction-specific symbolic categories, defined by the conventional syntactic, semantic, and morphological requirements of individual grammatical constructions (Kay \& Fillmore 1999; Croft 200I). Lexical items are compatible with a construction to the extent that they meet its requirements either by bearing the appropriate features, or by undergoing a context-induced typeshift (Michaelis 2003). We show that, for Cantonese, many distributional properties commonly thought to reflect differences in syntactic category status between verbs and adjectives in fact reflect construction-specific requirements that are independent of syntactic category. In section 4, we explore some typological implications of this study with respect to the theoretical predictions of Croft (I99I, 200I) and Baker (2003). With regard to Baker's (2003) claim that all languages have a syntactic category of adjectives, we suggest that the kinds of phenomena that he presents in support of this position may be viewed as semantically motivated construction-specific requirements rather than as evidence for a universal syntactic category. We then consider Croft's (I99I, 200I) proposal that adjectives are universal at the level of functional prototypes. In this case, we do find some subtle phenomena that fit Croft's predictions. We conclude that the functional prototype for adjectives may play a role in constraining the construction-specific categories of languages whose property words are categorized as verbs.

\section{Does Cantonese have a Category of adjectives?}

The syntactic status of words with adjective-like meanings has been a matter of some disagreement in linguistic studies on Chinese. In studies of Mandarin, a common view is that there is no syntactic category of adjective, but that 'adjectival verbs' represent a subclass of verbs (Li \&Thompson I98I; Cheung I994). However, McCawley (1992: 236) argues against a special subcategory of 'adjectival verb', on the grounds that the verbs concerned can be transitive, just like ordinary action verbs. He concludes that propertydenoting predicates in Mandarin are simply verbs. In contrast, Paul (2003) argues for a category of adjectives distinct from verbs, citing evidence from attributive modification constructions. However, she does not discuss the many similarities between verbs and (so-called) adjectives with respect to both predication and nominal modification.

Similar disagreements arise with respect to Cantonese. Matthews \& Yip (I994) and Yip (1985) note that adjectives are not clearly distinguished from verbs in Cantonese, opting tentatively for an adjectival verb analysis similar to that of Li \& Thompson (I98I). Mok (I998) also assumes an adjectival verb analysis in his study of comparative constructions in Cantonese. Lau (1999), however, argues for a distinct syntactic category of 'adjective' whose members 
have special properties, such as distinctive interpretations with aspect markers and the ability to participate in certain patterns of reduplication.

In section 2.I, we show that most words that translate as adjectives in English pattern as verbs in Cantonese, with the exception of a small number of attributive property words; while such words could constitute a small class of adjectives, their status does not affect the classification of other property words. In section 2.2 we focus on distributional variation within the category 'verb'. Crucial in this discussion are 'stative verbs' such as gengI 'be afraid' and beng6 'sick'. ${ }^{2}$ Matthews \& Yip (1994: 57, I3I) observe that such verbs appear to be intermediate between property verbs and action verbs: for example, geng I 'be afraid' behaves like an action verb in taking an object (see section 2.2.6), but like a property verb in allowing reduplication with -dei2 '-ish' (see section 2.2.5). In section 2.3 we will elaborate on the apparent intermediate status of these verbs, which show some properties typical of action verbs and others typical of property verbs. For descriptive purposes, we make reference to the semantically-based subclasses of property verb (e.g. hau6saangI 'young'), stative verb (e.g. gengI 'be afraid'), and action verb (e.g. sik6 'eat'), though we will conclude in section 2.3 that the overlapping patterns of distribution within the category 'verb' are not adequately explained in terms of syntactic category or subcategory labels.

\section{I General properties of verbs}

Before discussing variation among verbs in Cantonese, we first show what all verbs have in common. Verbs may be identified according to four diagnostics: (i) direct predication, (ii) negation, (iii) A-not-A question formation, and (iv) aspect marking. These properties are distinctive of verbs, and therefore not associated with predicate nominals.

\section{I.I Direct predication, negation, and A-not-A question formation}

All verbs can be used directly in main predicate position (i.e. without a copula) and allow negation with $m_{4}$ 'not', as shown in (I)-(3). (Note that subjects in Cantonese are not required to be overtly expressed.) Nouns used as predicates are usually supported by a copular verb, and can never be directly negated, as shown in (4).
(I) $\mathrm{M}$ haam.
('action verb')
not cry
'He's not crying.'

[2] The Cantonese examples are presented in the Jyut Ping romanization system, developed by the Linguistic Society of Hong Kong. See Matthews \& Yip (1994: 40of.) for correspondences between the Jyut Ping, the Yale, and the IPA systems. Tones are indicated only in citing individual words and morphemes. 


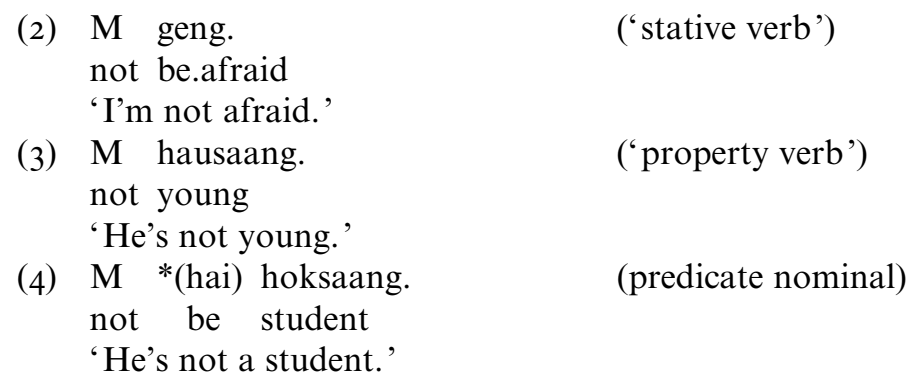

Verbs of all kinds also allow the A-not-A question formation typical of Chinese languages. In Cantonese this involves reduplication of the first syllable of the verb and infixation of the negative morpheme $m 4$ 'not'. Thus, in (5) and (6) the monosyllabic verbs haam3 'cry' and gengI 'be afraid' are reduplicated and $m_{4}$ is added, while in (7) only the first syllable of hau6saangI 'young' is reduplicated. Unlike verbs, nouns cannot undergo 'A-notA' question formation, (8a), but require the support of the copula, as in (8b). This is, of course, related to the fact that only verbs allow direct predication and combine directly with the negative marker $m 4$, as shown in (I)-(4) above.

(5) Bibi zung haam-m-haam aa?

('action verb')

baby still cry-not-cry PRT

'Is the baby still crying?'

(6) Lei geng-m-geng aa?

you be.afraid-not-be.afraid PRT

('stative verb')

'Are you afraid?'

(7) Keoi hau-m-hausaang aa?

s/he young-not-young PRT

('property verb')

'Is he young?'

(8) (a) *Keoi hok-m-hoksaang aa?

s/he student-not-student PRT

(predicate nominal) Intended: 'Is he a student?'

(b) Keoi hai-m-hai hoksaang aa?

s/he be-not-be student PRT

'Is he a student?'

This shared distribution shown in (I)-(3) and (5)-(7) supports the proposal that words with adjective-like meanings (property verbs), such as hau6saangI 'young' in (3), as well as those with stative meanings, such as gengI 'be afraid' in (2), belong to the same syntactic category as action verbs, such as haam3 'cry'.

\section{I.2 Aspect marking}

Verbs also allow at least some form of aspect marking. For example, the experiential marker gwo3, as in (9)-(II), is used to indicate a situation that 
has occurred at least once in the past. Again, words denoting states, (IO), and properties, (II), share this general property of verbs, but predicate nominals do not, (I2).

(9) Ngo dou haam-gwo.

('action verb')

I also cry-EXP

'I've cried too.'

(Io) Ngo dou beng-gwo.

I also sick-EXP

'I've been sick too.'

('stative verb')

(II) Ngo leigaai, ngo dou hausaang-gwo. ('property verb')

I understand I also young-EXP

'I understand, I was young once too.'

(I2) *Ngo leigaai, ngo dou hoksaang-gwo. (predicate nominal)

I understand I also student-EXP

Intended: 'I understand, I was once a student too.'

As in English, verbs may vary with respect to the range of aspect markers permitted and with respect to the semantic interpretation of aspect marking. We show in section 3 that such variation is determined by semantic factors, not syntactic category.

Almost all words denoting states, properties, and actions qualify as verbs according to the criteria given above. However, there is a small class of property words in Cantonese that occur only in attributive position modifying a noun and do not pass any of the diagnostic tests for verbs. One such word is gwokzai 'international', which typically appears in attributive position, as in (I3), but cannot be negated, as in (I4), for example.

(I3) $\mathrm{Ni}$ go hai gwokzai wui-ji.

This CL be international meeting

'This is an international meeting.'

(I4) *Ni go wui-ji m gwokzai.

this CL meeting not international

Intended: 'This meeting is not international.'

In a discussion of a similar class of property words in Mandarin, Paul (2003) proposes that such words - and in fact all property words-should be classified as adjectives. While we do not accept that ALL property words are adjectives, the existence of this minor class of non-verbal property words casts doubt on any claim that Cantonese completely lacks a category of adjectives. A plausible suggestion is that Cantonese has a small class of 'adjectives' that are restricted to attributive position. This does not, however, affect our analysis of variation within the category 'verb'. Below, we limit our attention to stative, action, and property words that have the distribution of verbs. 


\subsection{Variation within the category verb}

Having shown the distinctive properties of verbs in comparison with other syntactic categories, we proceed to discuss the problematic cases of grammatical variation among verbs. In particular, we show in this section that stative verbs pattern in three different ways:

(i) with property-denoting ('adjectival') verbs, with respect to comparison, interpretation of perfective aspect, and A-A-deiz reduplication;

(ii) with action-denoting verbs, with respect to transitivity and A-A-haa5 reduplication;

(iii) intermediate between property-denoting and action-denoting verbs, with respect to intensification.

\subsection{Direct comparison with gwo3}

Direct comparison takes the form [NP V gwo3 NP], where gwo3 is a grammaticalized comparative marker historically derived from the verb 'pass' (Mok 1998; Ansaldo 1999). This comparative construction is possible with property verbs and stative verbs, as shown in (I5) and (I6), but not action verbs, as shown in (I7).

(I5) Keoi gou gwo ngo.

$\mathrm{s} /$ he tall than me

'She's taller than me.'

(I6) Lei zung geng gwo ngo.

you still be.afraid than me

'You're even more afraid than I am.'

(17) *Keoi haam gwo ngo. s/he cry than me

Intended: 'She cried more than I did.'

Action verbs allow only a periphrastic form of comparison, using doI gwo 3 'more than', as in (I8) and (I9).

(I8) Lei sik dak do gwo ngo. you eat ADV more than me

'You eat more than I do.'

(19) Keoi haam dak zung do gwo ngo. s/he cry ADV still more than me

'She cried even more than I did.'

Interestingly, this distribution exactly matches that for Thai (Prasithrathsint 2000: 265f.), where adjectival and stative verbs allow direct comparison with $k w a ̀ a$ 'than' but action verbs require mâak kwàa 'more than', like Cantonese doI gwo3 'more than'. This is one of several respects in which the variation within the category 'verb' which we establish for Cantonese is very similar to that in Thai (see also note I8). 


\subsubsection{Intensification}

A property that might seem to distinguish adjectives (or adjectival verbs) from other verbs is modification by intensifiers such as hou ' 'very' and taai3 'too'. In fact, the possibilities here are complicated, especially in the case of houz. Let us first consider a straightforward intensifier such as taai3 'too', which can modify both property-denoting verbs, such as lekI 'smart' as shown in (20), and stative verbs, such as zungIjiz 'like' in (2I):

(20) Keoi muimui taai lek.

She sister too smart

'Her sister is too smart.'

(2I) Ngo taai zungji li fan gung.

I too like this $\mathrm{CL}$ job

'I like this job too much.'

However, taai3 cannot modify action verbs such as haang4 'walk', as shown in (22).

(22) *Keoi muimui taai haang.

s/he sister too walk

Intended: 'Her sister walks too much.'

This pattern matches that observed for comparative gwo 3 above: if there is a distinction here, it is between property verbs and stative verbs on the one hand, and action verbs on the other.

A more complex case involves the modifier hou ' 'very', which serves as a 'default' intensifier (corresponding to Mandarin hen). It regularly appears with property verbs such as lekI 'smart' in the absence of any other intensifier, as shown in (23).

(23) Keoi muimui hou lek.

$\mathrm{s} / \mathrm{he}$ sister very smart

'Her sister is smart.'

In this context hou 2 is semantically bleached, hence the translation 'smart' rather than 'very smart'. The same sentence without any intensifier, as in (24), seems incomplete:

(24) ?Keoi muimui lek. $\mathrm{s} /$ he sister smart

Although (24) is possible, it has a very restricted distribution, such as in response to a question or to contradict an assertion: ${ }^{3}$

[3] The marked character of the sentence is underlined by a distinctive emphatic (rising-falling) intonation on the predicate lekI (see Matthews \& Yip I994: 28). 
(25) A: Keoi muimui lek-m-lek aa?

s/he sister smart PRT

'Is her sister smart?'

B: Keoi muimui lek.

$\mathrm{s}$ /he sister smart

'Yes, she is (smart).'

Action verbs do not allow intensification, see (26), as already observed with taai3 in (22) above, while intensification is optional with stative verbs, as in $(27)$.

(26) *Keoi muimui hou haang. $\mathrm{s} /$ he sister very walk

(27) Ngo (hou) zungji li fan gung. I very like this CL job

'I like this job (a lot).'

Being optional as in (27), the intensifier hou2 'very' appears to have rather more semantic content when it occurs with stative verbs than with property verbs, where it is clearly semantically bleached. In this respect, stative verbs appear intermediate between action verbs and property verbs in their behaviour.

\subsubsection{Aspect marking and semantic interpretation}

Although all types of verbs permit at least some forms of aspect marking, differences of interpretation arise in some cases. In its canonical usage with action verbs, the perfective aspect marker $z 02$ indicates a completed event, as in (28).

(28) Keoi aam-aam zau-zo

s/he just-just leave-PFV

'He's just left.'

When combined with a property verb, (29), or stative verb, (30), the perfective marker typically takes on an inchoative reading:

(29) Lei houci fei-zo gam.

you seem fat-PFv thus

'You seem to have put on weight.'

(30) Keoi jigaa geng-zo lei.

$\mathrm{s}$ /he now be.afraid-PFV you

'He's become afraid of you now.'

Such interpretive differences between property and action predicates need not lead us to classify these stative and property predicates as adjectives, 
as is sometimes suggested (e.g. Lau 1999: 23-35). It is more straightforward to suppose that differences in interpretation arise from lexical semantic differences among the predicates. We shall elaborate this position in section 3.2 below in terms of a model of aspectual coercion.

\subsubsection{Attributive modification}

Bhat (I994: I02-IIO) presents evidence that in languages that have adjectives, their distinctive properties are more likely to show up in attributive constructions modifying nouns than in predicative constructions. However, Cantonese property words pattern similarly to other verbs in attributive constructions, as shown in (3I) and (32). In the most common form of nominal modification by verbs, the particle gez (corresponding to Mandarin de) occurs between the modifier and the head noun in the configuration [VP ge N].

(3I) cungming ge hoksaang

intelligent PRT student

'intelligent students, students who are intelligent'

(32) caamga ge hoksaang

take.part PRT student

'the students (who are) taking part'

Modification of the form [V N] (i.e. without ge) is also possible, but is semantically restricted in that the modifier represents a defining characteristic of the referent denoted by the NP (as discussed by Paul 2003 for Mandarin). The verb cannot take an object, nor can it be modified by an adverb, in the [V N] construction. Thus the [V N] pattern may be a form of compounding rather than a phrasal construction. Regardless of its syntactic status, however, it allows both intransitive property verbs and transitive stative verbs (suk 'familiar' can take a direct object in other contexts, see section 2.2.6 below), as shown in (33) and (34). The semantic restrictions noted above apparently rule out the possibility of action verbs in this construction.
(33) leng-leoi
('property verb')
cute-girl
'a beauty'
(34) suk-haak
('stative verb')
familiar-client
'regular customer'

As expected, we find that neither form of nominal modification in Cantonese is restricted to 'adjectival' property words. 


\subsubsection{Reduplication}

Reduplication is a highly productive process of derivational morphology in Cantonese, and it comes in a variety of forms. Some reduplication patterns appear characteristic of property verbs or - for those who assume that all words denoting properties are adjectives (e.g. Lau 1999)-of adjectives. However, of the three forms of reduplication discussed below each patterns in a different way: A-A-dei2 applies to property verbs and stative verbs, A-A-haa 5 to stative and action verbs, and A-B-B to property verbs and action verbs.

Reduplication of the form [A-A-dei2] applies to property verbs to achieve an attenuative meaning, as in (35). This process does not normally apply to action verbs, (36), while stative verbs typically pattern with property verbs in allowing it, (37).

(35) (a) hung4 'red' $\rightarrow$ hung4-hung2-dei2 'reddish'

(b) fei4 'fat' $\rightarrow$ fei4-fei2-dei2 'chubby'

(36) (a) haam3 'cry' but *haam3-haam2-dei2

(b) sik6 'eat' but *sik6-sik2-dei2

(37) (a) gengI 'be afraid' $\rightarrow$ gengI-gengI-dei2 'be a bit afraid (of something)'

(b) sikI 'know' $\rightarrow$ sikı-sikI-dei2 'know a little (of a language, etc.)'

In section 3.3 below, we propose a semantic account of these data, based on gradability.

The reduplication pattern [A-A-haa5] has an aspectual function which has been termed 'delimitative' - i.e. temporally bounded. ${ }^{4}$ Unlike A-A-dei 2 reduplication, these reduplicated forms can occur with action verbs but not property verbs:

(38) (a) haam3 'cry' $\rightarrow$ haam3-haam3-haa5 'cry for a while'

(b) fei4 'fat' but *fei4-fei4-haa5

Stative verbs are again intermediate in sometimes allowing the A-A-haa5 forms (typical of action verbs), as in (39) and (40), as well as the A-A-dei2 forms (typical of property verbs), as shown in (37) above.

(39) Keoi beng-beng-haa zau sei-zo.

s/he sick-sick-ASP then die-PFV

'After being sick for a while he died.'

(40) Keoi mong-mong-haa zau faatjin hai loupo saangjat. s/he busy-busy-ASP then discover be wife birthday

'After being busy for a while he realized it was his wife's birthday.'

[4] These forms are typically used in subordinate contexts, cf. Yip \& Matthews (200I: 75). 
One form of reduplication which might seem especially characteristic of property verbs is the $[\mathrm{ABB}]$ form:

(4I) bin2 'flat' $\rightarrow$ bin2-tet6-tet6 'dead flat'

(42) wan4 'dizzy' $\rightarrow$ wan4-to4-to4 'all dizzy'

In these forms, the reduplicant (B) is typically a syllable which cannot occur on its own and lacks lexical meaning, having at most a sound-symbolic value; indeed, it has been suggested that these reduplicants are ideophones comparable to those recognized in African languages such as Dagaare (Bodomo 2002). Although typically denoting properties, ABB forms may also be formed from action verbs, as in (43) and (44).

(43) siu3 'smile' $\rightarrow$ siu3-ke4-ke4 'smirk'

(44) zan3 'shake' $\rightarrow$ zan3-tang 4 -tang4 'tremble'

These examples have exactly the same properties as the more frequent 'adjectival' ABB forms (4I) and (42) in that the reduplicated syllable does not exist independently, but appears only in the ABB form. It has, at most, a sound-symbolic function: the reduplicant ke4 in (43), for example, is part of a family of onomatopoeic expressions used to describe laughter which begin with a [k] onset in Cantonese (such as the expression kaa4-kaa2-sengI siuz 'laugh out loud').

What we have shown, then, is that reduplication patterns define overlapping subclasses of verbs. The ABB pattern just described occurs with action verbs as well as property verbs, while stative verbs allow A-A-dei2 reduplication, characteristic of property verbs, as well as A-A-haa5 reduplication, characteristic of action verbs.

\subsubsection{Transitivity in stative verbs}

We have seen that stative verbs show mixed properties, patterning sometimes with action verbs and sometimes with property verbs. With regard to transitivity, stative verbs pattern with action verbs, many allowing direct objects, as in (45) and (46):

(45) Ngo hou cingco [NP ni gin si]. I very clear this $\mathrm{CL}$ matter 'I'm very clear about this matter.'

(46) Lei hou suk [NP ni di je]. you very familiar these CL things 'You're very familiar with these things.'

Direct objects in Cantonese, as opposed to other kinds of post-verbal NPs, are typically characterized by the possibility of (i) topicalization, and (ii) quantification with saai3. The objects of stative verbs are completely parallel to the objects of transitive action verbs with respect to these properties: they 
may be topicalized, as in (47) and (48), and quantified with saai3, as in (49) and $(50){ }^{5}$

(47) [NP Ni gin si] ngo zigei lei

this CL matter I self manage

'I'll deal with this matter myself.'

(48) [NP Ni gin si] ngo hou cingco _

this CL matter I very clear

'I'm very clear about this matter.'

(49) Lei sik saai di saanggwo.

you eat all CL fruit

'Eat up all the fruit.'

(50) Keoi suk saai di zi.

$\mathrm{s}$ /he familiar all CL character

'She's familiar with all those characters.'

Thus, stative verbs pattern like action verbs with respect to transitivity.

\subsection{Overlapping patterns of distribution}

To summarize, stative verbs pattern with action verbs with respect to A-A-haa5 reduplication (cf. section 2.2.5 above) and transitivity (cf. section 2.2.6), but with property verbs in allowing direct comparison with gwo3 (cf. section 2.2.I), intensification (cf. section 2.2.2), A-A-dei2 reduplication (cf. section 2.2.5), and an inchoative interpretation with perfective aspect (cf. section 2.2.3). How, then, should stative verbs best be classified?

A tempting solution is to posit two lexical entries for so-called stative verbs, one specified as a property verb (or adjective, for those who classify all property words as adjectives) and the other as a stative verb (or just as verb). Such an analysis is considered by McCawley (I992: 233) for Mandarin and suggested by Lau (I999: 37) to account for the transitivity of gengI 'be afraid' in Cantonese. Although there would be no discernible semantic difference between the two lexical entries, such an analysis is theoretically

[5] Contrast various kinds of post-verbal NP which are not true objects. For example, time expression NPs functioning as adjuncts cannot be quantified with saai3 (though they can be topicalized):

(i) *Keoi haam saai ni sam jat. s/he cry all these three day

Intended meaning: 'She cried for all three days.'

Conversely, a post-verbal NP following comparative gwo3 (see section 2.2.I) can be quantified with saai3, but cannot be topicalized:

(ii) $*$ NPP ni di jan] lei lek gwo
these people you smart than

Intended meaning: 'You're smarter than these people.' 
possible, given that languages may have synonyms belonging to different word classes (e.g. envy vs. envious in English). However, such a solution fails to account for the possibility of words like ganIzoengI 'worried' and suk6 'familiar' behaving SIMULTANEOUSLY as a property verb/adjective (in allowing comparison with gwo3) and as a transitive stative verb (in taking an object which can be topicalized), as in (5I) and (52).

$$
\begin{aligned}
& \text { [Di sailouzai] lei zung ganzoeng _ gwo ngo. } \\
& \text { CL kids you still worried than me } \\
& \text { 'You're even more worried about the kids than I am.' }
\end{aligned}
$$

(52) [ $\mathrm{Ni}$ di je] lei ganghai suk _ gwo ngo laa. this CL stuff you of-course familiar than me PRT

'Of course you're more familiar with this stuff than I am.'

Still maintaining a traditional approach, stative verbs could simply be classified as a subcategory of their own, distinct from property verbs and action verbs but overlapping with both types of verbs in their distribution. However, such an approach misses an important point: many of the distributional possibilities of these various verb classes are predictable from the lexical-semantic and phonological properties of individual verbs. In the following section, we elaborate on this point and propose a feature-based analysis framed within a parallel-architecture theory of grammar to capture more adequately the distributional variation discussed above.

\section{A MULTI-Dimensional APPROACH TO VARIATION WITHIN THE CATEGORY 'VERB'}

As noted in section I, formal syntacticians commonly assume that the distinctive grammatical properties of each lexical category can be captured by syntactic features or feature matrices (Chomsky I970, I98I; Jackendoff I977; Déchaine 1993). Chomsky (198I) defines the lexical categories 'noun', 'verb', 'adjective', and 'preposition' as follows:
(53) Verb: $[+\mathrm{V}-\mathrm{N}]$
Noun: $[-\mathrm{V}+\mathrm{N}]$
Adjective: $[+\mathrm{V}+\mathrm{N}]$
Noun: $[-\mathrm{V}+\mathrm{N}]$
Preposition: $[-\mathrm{V}-\mathrm{N}]$
(Chomsky 198I: 48)

According to this scheme, every verb has the syntactic features $[+\mathrm{V}-\mathrm{N}]$ specified in its lexical entry and, as a consequence, can participate in syntactic configurations that call for verbs. Categories are not defined by distributional patterns in particular languages; rather, distributional patterns are derivative of the feature specifications. In section I, we noted that this sort of feature system does not address the problems of cross-linguistic variation in category systems and variation among members of the same category: at the least, such a feature system must be supplemented with additional mechanisms for dealing with variation. This section focuses on the problem of within-category variation, proposing a multi-dimensional 
theoretical approach, while section 4 will focus on the cross-linguistic problem.

\section{I Overview of the multi-dimensional theory}

We have shown in section 2 that for Cantonese, no single combination of distributional properties is characteristic of all verbs, or even of a particular subcategory of verbs. Clearly, whatever syntactic features are common to all verbs (however these features might be defined within a particular theory) cannot account for these overlapping patterns of distribution. Rather, a more finely articulated approach is needed.

In section I, we discussed two general approaches to this problem that have been proposed in the literature: (i) the prototype-based approach of functional-typological theories, and (ii) the multi-dimensional feature-based approach of parallel architecture theories. Francis (I999) and Malouf (2000) show that these two types of approach are in fact compatible with each other: the prototype-based approach predicts general patterns of markedness both within and across languages, while the multi-dimensional approach shows how specific morphological, syntactic, and semantic factors interact to produce the actual distributional patterns in a language. Our analysis adopts elements of both approaches.

Our approach is based on the multi-dimensional theory of lexical categories proposed in Francis (I999) to account for variation within the lexical categories noun, verb, and adjective in English. It also incorporates the idea of construction-specific category from Croft's (200I) theory of Radical Construction Grammar, and is broadly compatible with the treatment of lexical categories in any of the parallel-architecture frameworks, including Autolexical Grammar (Sadock I990, I99I), HPSG (Pollard \& Sag I994; Malouf 2000), Lexical-Functional Grammar (Bresnan I995), Representational Modularity (Jackendoff I997, 2002), and Construction Grammar (Kay \& Fillmore I999). For concreteness, we use the framework of Autolexical Grammar (Sadock I99I) - a multi-modular framework in which independent but interacting components of syntax, semantics, and morphology are represented simultaneously and in parallel. Unlike approaches to formal syntax which place the bulk of explanatory power in the syntactic component of grammar (e.g. Chomsky I995), Autolexical Grammar places the syntactic component in a role equal in importance to that of semantics, morphology, and phonology. Syntax consists primarily of categories, phrase structure, and subcategorization, while phenomena such as argument structure and co-reference are dealt with at the level of semantics.

As in mainstream formal theories of syntax (e.g. Chomsky I98I, I995), we represent a word's membership in a lexical category such as noun, verb, or adjective as a syntactic feature. Such categories are part of an autonomous level of syntax at which purely syntactic information is represented 
independently from semantic and pragmatic information. Although a justification for this position is beyond the scope of the present paper, Bresnan (1995) and Yuasa \& Francis (2003) provide extensive justification in their discussions of categorial mismatches between syntax and semantics. ${ }^{6}$ Shapiro \& Caramazza (2003) also support this view with converging neurological evidence from studies on both brain-damaged and normal individuals, suggesting that the syntactic category of a word is represented independently of its meaning in both the mental lexicon and the processes of morphological and syntactic computation.

Although we use syntactic category features, our feature system differs from Chomsky's in certain respects. First, as Newmeyer (I998: I78f.) points out, the Chomskian system restricts the possible natural classes of lexical categories to those which share category features, excluding other classes which appear to be empirically motivated. For example, although adjectives and prepositions share no features, some prepositions in English are historically derived from adjectives (e.g. like). ${ }^{7}$ To address this problem, our feature system does not break down categories into sets of binary features that define natural classes, but rather each category has its own feature: $[\mathrm{N}]$, [V], etc. Secondly, Baker (2003) points out that the Chomskian feature system is largely devoid of content, since the features themselves do not make any specific predictions about the grammatical behaviour of items bearing them (this of course contributes to the first problem too, since it is impossible to identify natural classes if we do not know which syntactic behaviours are relevant). We address this issue by associating each syntactic category feature with the language-specific phrase-structure configurations characteristic of that category. For example, the syntactic category [V] in Cantonese is associated with the basic configuration in (54).

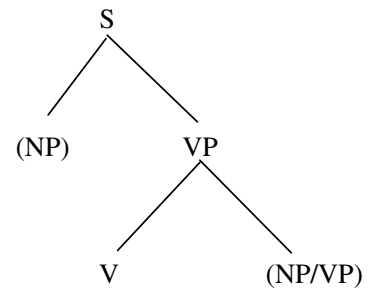

By defining syntactic categories in terms of language-specific syntactic patterns, we reject the assumption widely held in generative grammar that at least some syntactic categories are innate and universal. Culicover (I999: 37-4I) lends support to this view from the perspective of language learning. $\mathrm{He}$ argues that since ALL syntactic categories and subcategories must be

[6] See also Newmeyer (1998: 25-55) for a general defense of the autonomy of syntax hypothesis.

[7] See also Baker (2003: I-3) for discussion of this problem. 
learned on the basis of language-specific facts, there is nothing to be gained by distinguishing between universal categories such as 'noun' and 'verb' and language-specific categories such as 'pronoun' and 'count noun'. Rather, it is more straightforward to assume that all categories are defined on the basis of language-specific distributional evidence available to the language learner. Culicover argues that cross-linguistic similarities among category systems can be understood in terms of the universally-instantiated categories of semantic structure (see Croft 200I for a similar view). Any similarities between Turkish verbs and Cantonese verbs, for example, can be attributed to the fact that verbs in any language typically express the semantic predicate of a proposition: indeed, this is why we call both categories by the same label 'verb', despite their obvious syntactic and morphological differences. Following Croft (200I: 50), we do not assume that 'verb' in Cantonese is the same category as 'verb' in Turkish or any other language, but rather we use the label 'verb' to indicate the syntactic category whose members are prototypically used as semantic predicates in a particular language.

Category information is specified not only at the level of syntax, but also at the independent levels of (inflectional) morphology and semantics. The morphological category $[\mathrm{V}]$ is associated with the morphological inflections characteristic of verbs. In the case of Cantonese, morphological verbs are associated with the possibility of aspect marking. Likewise, in semantic structure, there is a category [Pred] (predicate), which combines with a specified number of arguments to form a proposition. This category is typically expressed by verbs, but can also be expressed by words of other morphological and syntactic categories. For example, the semantic predicate is expressed by a noun phrase in predicate nominal constructions.

Following Sadock (1990), we posit DEFAULT CORRESPONDENCES of syntactic, semantic, and morphological features to capture the canonical associations of category information from different levels of grammar. The default correspondences, or prototypes, for the categories 'noun' and 'verb' in Cantonese are given in (55) and (56). We return to this point in section 4.2 below.

(55) Prototype for 'verb' in Cantonese

Syn: V

Morph: V

Sem: $\quad$ Pred

(56) Prototype for 'noun' in Cantonese ${ }^{8}$

Syn: N

[8] Following Sadock (1990: 27If.), we use the term CN to represent the unique semantic properties of common nouns. CNs differ from ordinary predicates in bearing a 'criterion of identity' (Gupta 1980: 22), which makes it possible to judge whether X is the same as Y, and which allows the referents of nouns to be counted and measured. See also Baker (2003: IOI-I69) for extensive discussion. 
Morph: $\mathrm{N}$

Sem: $\quad \mathrm{CN}$, Arg

As argued in Croft (I99I, 200I), the semantic content of the prototypes is similar across languages: nouns typically express arguments and verbs typically express predicates in all languages that have these categories. However, the morphological and syntactic configurations associated with the category features differ across languages.

Although the prototypes given in (55) and (56) represent strong tendencies, there are exceptions. For example, the copula hai6 'be' occurs in syntactic configurations typical of verbs, but has no obvious semantic content distinct from the semantic content of the predicate nominal that it introduces, and never occurs with aspect marking, as shown by (57).

(57) Ngo cangging hai (*-gwo) hoksaang.

I once be exp student

'I was once a student.'

The copula hai6 might then be analyzed as a syntactic verb that is unspecified for morphological and semantic category. Cross-level mismatches of this sort are thus one potential source of grammatical variation among verbs in Cantonese. ${ }^{9}$

With respect to the data presented in section 2, a more significant source of variation among verbs involves construction-specific constraints. Supplementing the general architecture of Autolexical Grammar, we assume a notion of 'construction' as in Construction Grammar (Goldberg I995; Kay \& Fillmore I999). Similar to lexical items, the grammatical constructions of a language are conventional symbolic units, consisting of form and meaning, and each construction is listed individually in the lexicon. Although constructions often lack any phonological specification, they typically consist of correspondences of morphological, syntactic, and semantic features. In this view, a lexical item is compatible with a given construction to the extent that its features (including, but not limited to, syntactic category features) are compatible with the construction's features. Following Croft (200I : 45-47), we identify the class of lexical items that fits into a particular slot of a construction as a construction-specific category. For example, the particular class of verbs that fits into the ' $\mathrm{V}$ ' slot of the Cantonese comparative construction [NP V gwo3 NP] is a constructionspecific category (see examples (I5)-(I7) above). We show in the following

[9] Francis \& Michaelis (2003a: 4f.) identify two kinds of mismatches that can contribute to within-category variation. The case of the copula hai6 'be' in Cantonese is a 'complexity mismatch' because the syntax contains more elements of structure than the semantics. The case of English quantificational nouns such as lot (Yuasa \& Francis 2003) is a 'content mismatch' because the syntactic category 'noun' is associated with a semantic category that would normally be associated with a different syntactic category. 
section that the comparative construction with gwo 3 imposes specific limitations on the verbs it combines with, allowing only verbs bearing the semantic feature of gradability.

We have identified four different types of categories: syntactic categories, morphological categories, semantic categories, and construction-specific categories. However, we acknowledge that there is a sense in which all of these category types are construction-specific. ${ }^{10}$ For example, we said that syntactic categories are characterized by the possibility of occurring in a particular set of phrase-structure configurations. If we take the Construction Grammar view that phrase-structure configurations are abstract constructions (e.g. Kay 2002), as opposed to the more traditional view that they are formed by phrase-structure rules, then syntactic categories such as 'noun' and 'verb' are indeed construction-specific categories which happen to include a large number of members. Jackendoff (2002: I79f.) points out that viewing phrase-structure configurations as constructions is useful, in that it unifies the treatment of idioms with the treatment of 'core' syntax. However, he argues that phrase-structure constructions are 'defective' in the sense that they lack any semantic specification, and thus are not symbolic in nature. This is in contrast to linguists such as Langacker (I99I), who contend that even phrase-structure constructions are meaningful, albeit on a very abstract level.

Jackendoff's approach is fully compatible with the architecture of Autolexical Grammar, and it is also useful for capturing certain generalizations. For example, characterizing phrase-structure constructions (and the categories defined by these constructions) as purely syntactic allows us to capture the fact that the copula hai6 'be' in predicate nominal constructions occurs in phrase-structure configurations typical of transitive verbs (i.e. as head of a VP taking an NP as its complement) even though it is not a semantic predicate. If the syntactic category 'verb' is, in principle, independent of the semantic properties of any particular symbolic construction, then the fact that it occurs in different symbolic constructions with quite different semantic properties is easy to explain. Thus, while acknowledging that it is useful to think of syntactic categories as construction-specific in the sense that they occur in abstract constructions, we maintain, following Jackendoff (2002), that their characterization does not depend on the semantic requirements of any particular symbolic construction. In contrast, what we had referred to above as 'construction-specific categories' are subject to the requirements of symbolic constructions. For example, as we will show in section 3.2, the subcategory of verbs allowed in the Cantonese comparative construction is constrained by the semantic requirements of this particular construction. For clarity, we will refer to categories such as these as symbolic

[Io] We are grateful to an anonymous $J L$ referee for pointing out that syntactic categories can be characterized in terms of constructions. 
categories, in contrast to (purely) syntactic categories, such as 'verb', and (purely) semantic categories, such as predicate.

In section 3.2, we account for the overlapping patterns of distribution discussed in section 2 in terms of the compatibility of various lexical items, all of which belong to the same syntactic category 'verb', with the phonological, syntactic, and semantic requirements of particular symbolic constructions.

\subsection{A multi-dimensional analysis of variation among Cantonese verbs}

In this analysis we show how an interaction of factors from syntax, semantics, and phonology results in the overlapping patterns of distribution presented in section 2. Most of the observed distributional patterns result directly from the compatibility or incompatibility of the lexical features of individual verbs with features of the constructions with which they combine. In a few cases, features of the construction override otherwise incompatible features of the lexical items, inducing an aspectual type-shift (Smith I997; Ross 2002; Michaelis 2003). We begin by elaborating on the properties that are common to all verbs.

\subsection{Syntactic category features: $[V]$}

The morphological feature [V] and the syntactic feature [V] play an important role in determining the distribution of Cantonese verbs and in distinguishing verbs from nouns. As argued in section 3.I, the morphological feature [V] licenses aspect marking on verbs; nouns lack this morphological feature and cannot take aspect marking (see section 2.I.2 above for examples).

Other properties of verbs, for example, the fact that verbs act as the main predicate of a clause (without a copula), follow from the phrase-structure construction associated with the syntactic category [V], as given in (54) above. However, the possibility for main-clause predication apparently does not distinguish verbs from nouns in all cases. Although predicate nominals typically occur with the support of a copular verb, as in (58), they can also occur in what appears to be main predicate position, as in (59), when an appropriate sentence-final particle is included.

(58) $\mathrm{Ni}$ go (hai) ngo pangjau leigaa.

This CL is ISG friend PRT

'This is my friend.'

(59) $\mathrm{Ni}$ go zai wo.

This CL boy PRT

'This one is a boy.' 
However, predicate nominals can never be negated with $m_{4}$ 'not', nor can they undergo A-not-A question formation, without the support of a copular verb; (60)-(62) illustrate.

(60) $\mathrm{Ni}$ go $\mathrm{m} *$ (hai) ngo pangjau leigaa.

this CL not be ISG friend PRT

'This is not my friend.'

(6I) *Ni go zai $m$ zai aa?

this CL boy not boy PRT

Intended: 'Is this one a boy?'

(62) $\mathrm{Ni}$ go hai $\mathrm{m}$ hai zai aa?

this CL be not be boy PRT

'Is this one a boy?'

This is all evidence in favour of a formal syntactic feature [V], which nouns lack, licensing these properties. The possibility of main-clause predication with predicate nominals, as in (59), may therefore be the result of a kind of ellipsis, whereby a copular verb is present in the syntactic structure but not pronounced (cf. Matthews \& Yip 1994: 129). This would be consistent with an account in which negation with $m_{4}$ and A-not-A question formation apply only to an overtly expressed lexical item in main predicate position. An alternative explanation, and one that is more in keeping with the surface-oriented conception of syntax assumed here, is that mainclause predication is possible for nouns as well as verbs, and that the differences between them are due to specific constructional requirements. According to this account, the negation construction and the A-not-A question construction only license predicates belonging to the syntactic category [V]. Although these constructions are symbolic in nature, the exclusion of predicative nouns from the ' $\mathrm{V}$ ' position in these constructions in (60)-(62) appears to have no semantic basis. It seems plausible, then, that the negation construction and the A-not-A question construction inherit syntactic properties (including the requirement for a verbal predicate) from the more general phrase-structure construction given in (54) above. On the other hand, the predicate nominal with sentence-final particle construction licenses NP predicates. Importantly, this construction does not conform to the phrase-structure construction in (54). If it did, it would require a copular verb. Rather, it is an exceptional construction which licenses NPs as predicates only in the presence of an appropriate sentencefinal particle.

The configuration in (54) above also implies transitivity in verbs that select two semantic arguments. As shown in section 2.2.6 above, two-argument verbs denoting both states and actions can take direct objects. Nouns do not share this feature, and therefore two-argument nouns such as pang4jau5 'friend' cannot take a direct object, as in (63). They must instead 
occur in a possessive construction to express both of their arguments, as in (64).

* Ngo hai pangjau keoi muimui.

I be friend $\mathrm{s} /$ he sister

Intended: 'I am a friend of his sister.'

(64) Ngo hai keoi muimui ge pangjau.

$\mathrm{s} / \mathrm{he}$ be s/he sister PRT friend

'I am his sister's friend.'

\subsubsection{Semantic features: [gradable], [dynamic]}

Semantic features alone, in particular gradability and dynamicity (Croft I99I: 65), are responsible for most of the grammatical patterns that distinguish action verbs from property verbs and stative verbs. We shall observe that semantic features, unlike syntactic features, are gradient rather than discrete. That is, some lexical semantic features may be instantiated to different degrees in different words, and semantic interpretations of the same word may vary according to context.

The feature [gradable] denotes a gradient scale, allowing us to talk about the degree to which a certain state or property holds. For example, the English word tall bears the feature [gradable], licensing expressions such as taller, very tall, and kind of tall. In many languages the lexical semantic feature [gradable] is associated with the syntactic category of adjectives, helping to define the prototype for this category (Croft I99I: 67). This cannot be so for languages like Cantonese, for which most gradable property words are verbs. Instead, we propose that for several of the constructions that are similar to adjectival constructions in other languages, the semantic feature [gradable] determines which verbs are licensed. For example, to the extent that the meaning of a verb is gradable, it can occur in the direct comparison construction [NP V gwo3 NP]. Thus, direct comparison is possible both with verbs denoting gradable properties, such as gouI 'tall', as in (65) below, as well as with gradable states, such as gengI 'be afraid', as in (66). Direct comparison is not possible with verbs such as sik6 'eat', denoting non-gradable actions, as is shown in (67). Relatively non-gradable property verbs, such as $\mathrm{co}_{3}$ 'wrong', are normally infelicitous with direct comparison as well (68).

(65) Keoi gou gwo ngo.

(gradable property)

s/he tall than me

'She's taller than me.'

(66) Lei zung geng gwo ngo. (gradable state)

you still be.afraid than me

'You're even more afraid than I am.' 
* Lei sik gwo ngo. (non-gradable action) you eat than me

Intended: 'You eat more than I do.'

?*Keoi co gwo ngo. (non-gradable property)

$\mathrm{s} /$ he wrong than me

Intended: 'She's more wrong than I am.'

Likewise, the intensification construction, consisting of an intensifying adverb followed by a verb (cf. section 2.2.2 above), licenses gradable verbs, as in (69) and (70), but not non-gradable verbs, as in (7I).

(69) Keoi muimui taai lek.

$\mathrm{s} /$ he sister too smart

'Her sister is too smart.'

(70) Lei taai zungji li fan gung.

you too like this CL job

'You like this job too much.'

(71) *Keoi muimui taai haang. $\mathrm{s} /$ he sister too walk

Intended: 'Her sister walks too much.'

As expected, default intensification with houz only occurs with gradable property verbs, such as lekI 'smart' in (72). As noted in section 2.2.2, gradable verbs denoting properties are often less felicitous without any intensifier, as in (72), and they normally occur with the intensifier hou2 in the absence of any other intensifier. With these verbs, hou2 'very' has little if any meaning. In contrast, the property verb $\mathrm{co}_{3}$ 'wrong' in (73) is not readily gradable in Cantonese, and therefore we get the opposite judgments: no intensification is preferable to default intensification. Thus, even though the meaning of hou is bleached when it occurs with property verbs, the intensification construction in which it occurs still licenses only semantically gradable verbs.

(72) Lei ?*(hou) lek wo.

you very smart PRT

'You're (very) smart.'

(73) Lei (?*hou) co ge laa.

you very wrong PRT PRT

'You're (very) wrong.'

The feature [dynamic], associated with so-called action verbs, denotes a process involving some kind of internal change. This feature also contributes to variation within the category verb in Cantonese; however, the variation is in semantic interpretation rather than in distribution. As discussed in section 2.2.3 above, both dynamic and non-dynamic verbs allow perfective marking 
with zo2, but they are interpreted somewhat differently. In (74), for example, perfective marking with [dynamic] verbs yields the expected eventive interpretation. But verbs that lack the feature [dynamic], i.e. verbs that denote an internally homogeneous state or property, usually acquire an inchoative interpretation when combined with perfective zO2, as shown in example (75). ${ }^{11}$

(74) Keoi zeoigan zaan-zo hou do cin.

$\mathrm{s}$ /he recently earn-PFv very much money

'She's earned a lot of money recently.'

(75) Keoi zeoigan hoisam-zo hou do.

s/he recently happy-PFV very much

'She's become much happier recently.'

The perfective construction in Cantonese of the form [NP V zor (NP)] denotes a completed action or event. We hypothesize that the meaning inherent in the perfective construction 'coerces' a dynamic change-of-state interpretation when combined with a non-dynamic verb. This is analogous to the coercion of English adjectives, as in (76).

(76) They were bored in Io minutes. (Michaelis 2004: 17)

As observed by Michaelis (2004: 17), the construction that contains the 'frame adverbial' PP in Io minutes coerces an inchoative reading when combined with a stative adjective. The type shift in (76) involves the addition of a transition to the temporal representation of the state denoted by the adjective bored. Thus, while a stative predicate such as bored would normally be used to express a steady psychological state, it is used in (76) to express a change of state. This does not, however, change the syntactic category of the adjective bored. Similarly, there is no reason to suppose that a change of syntactic category (e.g. adjective-verb conversion) occurs in Cantonese in examples like (75) above. $^{12}$

[II] Other interpretations are also possible when perfective marking combines with a stative verb. For example, in (i) the predicate sikI 'know' when combined with perfective $z o 2$ and a time adverbial expression denotes a delimited period up to and including the present:

(i) Ngodei sik-zo sap lin.

we know-PFv ten year

'We've known each other for ten years.'

[12] An anonymous $J L$ referee points out that the application of 'coercion' in these cases is language-specific and conventional, suggesting that there is one construal for 'verbs' and another for 'adjectives'. However, in our view, the fact that coercion is subject to languagespecific constraints has no bearing on the syntactic category status of these predicates. Coercion applies to a semantically-defined subclass of verbs whose syntactic category is unaffected by the coercion operation. Note also that coercion applies equally to property verbs and stative verbs, as shown in (29) and (30). 
One way to understand this phenomenon is in terms of Michaelis' Override Principle:

If a lexical item is semantically incompatible with its syntactic context, the meaning of the lexical item conforms to the meaning of the structure in which it is embedded. (Michaelis 2004: 25) ${ }^{13}$

In the case of (76), the meaning of the adjective bored, which normally implies no temporal boundaries, conforms to the meaning of the frame adverbial construction, which requires that the event culminate within the time frame denoted by the PP. In taking on an inchoative interpretation, the predicate bored acquires a transition which makes this temporal bounding possible (Michaelis 2004: 3I). We can account similarly for the inchoative reading of (75). The perfective marker $z 02$ is the semantic head of a partially lexically filled perfective construction. When this construction combines with a stative predicate, there must be some way of resolving the conflict between the stative meaning of the predicate, which is not delimited in time, and the meaning of the perfective construction, which imposes a temporal boundary on the event. In such cases, the conflict is resolved according to the Override Principle: the meaning of the construction wins out, forcing the stative predicate (hoiIsamI 'happy') into an inchoative interpretation so that a bounded, perfective interpretation for the sentence becomes possible (hoiIsamI-zo2 'has become happier'). ${ }^{14}$

\subsubsection{Phonological features, semantic features, and reduplication}

The reduplication facts discussed in section 2.2.5 above can be handled in terms of the interaction of semantic and phonological features. The features [monosyllabic] and [gradable] are required for A-A-deiz reduplication, as discussed in section 2.2.5 above.

Because of the attenuative meaning of A-A-deiz reduplicated forms, A-Adei2 reduplication requires as its input a base with the feature [gradable].

[13] A similar proposal is Smith's (1997: 53) Principle of External Override: 'In a clash between the verb constellation and an adverbial, the adverbial overrides'. However, Michaelis' proposal makes more general predictions. A construction need not have any lexical instantiation to create a coercion effect. For example, a constructional view of override can account for count-mass coercion involving bare nouns, as in You have apple on your shirt (Michaelis 2003: 270).

[I4] An important theoretical issue raised by these examples is the problem of how coercion is constrained. Michaelis (2004 and p.c.) proposes the following constraints on the application of the Override Principle. First, both the input and output to coercion must be preexisting lexical types in a particular language. Secondly, coercion can add at most one component of meaning to the Aktionsart representation. In the case of the state-inchoative shifts discussed in this paper, a transition is added to the meaning of the stative (nondynamic) verb. Unfortunately, a detailed discussion of these issues is beyond the scope of the present paper. 
Since haam3 'cry' in (77c) is non-gradable, it is not felicitous with A-A-dei2 reduplication.

(77) (a) hung4 'red' $\rightarrow$ hung4-hung2-dei2 'reddish'

(b) gengI 'be afraid' $\rightarrow$ gengI-gengI-dei2 'be a bit afraid (of something)'

(c) haam3 'cry' but *haam3-haam2-dei2

Reduplication of polysyllabic verbs is also possible, but only where the reduplicated material can be interpreted as a distinct morpheme in a morphologically transparent compound:

(78) (a) paa3-cau2 'shy' (literally 'fear-ashamed') $\rightarrow$ paa3-paa3-dei2-cau2 'rather shy'

(b) sin6-mou6 'envious' (non-transparent) but *sin6-sin6-dei2-mou6 (intended meaning: 'rather envious')

In (78a), reduplication applies to the element paa3 'fear' but in (78b), the syllable $\sin 6$ is not interpretable as a separate morpheme and thus reduplication is not possible. In a case such as (78a), paa3 is interpretable as a single (monosyllabic) word at the level of syntax, even though for semantic reasons it is listed in the lexicon together with cau2. Thus, paa3-cau2 'shy' may be more comparable to English idioms like keep tabs on than to compound words like blackbird.

A-A-haa5 reduplication is similarly constrained. The semantic feature [permanent] denotes the potential for stability over time. This feature, inherent in many property predicates, is incompatible with the delimitative (temporally bounded) meaning of the reduplicated forms: $:^{15}$

(79) (a) sik6 'eat' $\rightarrow$ sik6-sik6-haa5 'eat for a while'

(b) beng6 'sick' $\rightarrow$ beng6-beng6-haa5 'sick for a while'

(c) fei4 'fat' but *fei4-fei4-haa5 (intended: 'fat for a while')

Although it is possible, for example, to speak of someone eating for a while (79a) or being sick for a while (79b), it is not normally possible to speak of someone being fat for a while (79c) because fatness is a relatively permanent property. Thus, verbs with the feature [permanent] disfavour this form of reduplication.

Some verbs lexically specified as [permanent] do allow A-A-haa5 reduplication, but in such cases these verbs are no longer conceptualized as permanent. Examples (80) and (8I) below make a useful comparison. In (80), the verb mong 4 'busy' is not inherently permanent, and therefore fully compatible with A-A-haa5 reduplication. In contrast, the verb sikI 'know' in

[15] Our feature [permanent], from Croft (I99I: 65), is equivalent to the idea of individual-level predicate (as opposed to stage-level predicate) as used in Carlson (I977). 
the sense of knowing someone is lexically specified as [permanent]. When sikI undergoes A-A-haa5 reduplication, as in (8I), knowing someone is no longer conceptualized as a permanent property; rather, it takes on an inchoative meaning of 'getting to know' - a meaning which can more easily be delimited in time.

(80) Keoi mong-mong-haa zau faatjin hai loupo saangjat $\mathrm{s}$ /he busy-busy-ASP then discover be wife birthday 'After being busy for a while he realized it was his wife's birthday.'

(8I) Ngodei sik-sik-haa, zau faatgwok daaigaa hai Ciuzau jan. we know-know-ASP then discover both are Chiuchow people 'After getting to know each other a bit, we found out we were both Chiu Chow people.'

We suggest that (8I) is an instance of aspectual coercion similar to that discussed above in section 3.2.2. Similar to example (75) above, the Override Principle applies in (8I): the delimitative meaning of the A-A-haa5 construction overrides the [permanent] meaning of the verb sikI, forcing the verb into a non-permanent (in this case inchoative) interpretation. ${ }^{16}$

\subsubsection{Understanding the putative subcategories as clusters of semantic features}

We have argued that all verbs share the syntactic feature [V], which allows them to occur in constructions involving transitivity, negation with $m 4$, and A-not-A question formation. With only a couple of exceptions such as the copula hai6, verbs also share the morphological feature [V], which allows them to combine with aspect marking. We have also shown that grammatical variation among verbs can be understood in terms of the compatibility or incompatibility of each verb's lexical semantic and phonological features with the corresponding features of various constructions. These lexical features are, in principle, independent from each other, so that many combinations of features are possible. However, certain combinations appear to be particularly common.

We are now in a position to redefine our original heuristic subcategories of 'action verb', 'stative verb', and 'property verb' in terms of clusters of lexical semantic features, bearing in mind that these three clusters are not the

[I6] Why, then, don't [permanent] predicates always allow coercion? Most likely for pragmatic reasons. For example, the idea of 'getting fat for a while' is pragmatically implausible in most situations, but our native speaker consultants tell us that under the right pragmatic conditions many [permanent] predicates can undergo coercion and A-A-haa5 reduplication. For example, the following sentence is fine in a context in which a patient has been given a diet in order to put on weight:

(i) Fei-fei haa, zau mou zoi fei.

fat-fat-ASP then not-have again fat

'After putting on weight for a while s/he ceased to do so any more.' 
only possible feature combinations. So-called action verbs ('throw', 'eat') bear the semantic feature [dynamic], allowing them to receive an eventive interpretation when combined with perfective aspect marking. Property verbs ('tall', 'fat') lack the feature [dynamic], thus receiving an inchoative interpretation when combined with perfective marking. Instead, property verbs typically bear the feature [gradable], allowing them to participate in constructions involving direct comparison with gwo3, A-A-deiz reduplication, and intensification. In addition, property verbs bear the feature [permanent], causing them to be incompatible with the delimitative meaning of $A$ - $A$-haa 5 reduplication. Stative verbs ('worry', 'busy', 'afraid') share semantic features with both action and adjectival verbs: they are nonpermanent (transient), like action verbs, but non-dynamic and (to some extent) gradable like property verbs. To the extent that stative verbs are gradable, they allow comparison with gwo3, intensification, and A-A-dei2 reduplication, as shown in section 3.2.2 above. However, because they lack the feature [permanent], stative verbs do not resist A-A-haa 5 reduplication in the way that property verbs do.

In the following section, we consider some of the typological implications of these findings in the context of the competing theoretical predictions of Croft (200I) and Baker (2003).

\section{Typological implications: AdjeCtives as A UNIVERSAL CATEGORY?}

The grammatical behaviour of Cantonese verbs has implications for both theoretical problems with which we began: (i) the problem of cross-linguistic variation with respect to lexical categories, and (ii) the problem of grammatical variation among members of the same lexical category within a particular language. In response to problem (ii), we have proposed that grammatical constructions allowing verbs may impose specific morphological, semantic, and syntactic requirements beyond those specified by syntactic features such as [V], thus defining a number of overlapping constructionspecific categories within the category of verbs. We now turn to the problem of cross-linguistic variation among category systems.

Two important current theoretical approaches to the universals and typology of lexical category systems are laid out in Croft (I99I, 200I) and Baker (2003). These two approaches are rather difficult to compare because they are based on such different theoretical assumptions: Croft's functionaltypological approach focuses on semantic-pragmatic prototypes to account for universal and typological patterns, while Baker's P\&P- (Principles-andParameters) style approach focuses instead on purely syntactic principles. However, since our own parallel-architecture approach occupies a theoretical middle ground between them, and since parallel-architecture theories have not yet dealt with this issue in any comprehensive way, we find it 
instructive to explore the typological implications of our study with respect to the predictions of Baker and Croft.

One of our claims in section 2 was that the vast majority of propertydenoting words in Cantonese are verbs. Although some constructions, such as comparatives, appear to be 'adjectival' in nature, we argue in section 3 that they are actually verbal constructions that are sensitive to certain semantic and phonological features of individual verbs. This idea that Chinese lacks adjectives (or has only a small class of non-verbal property words) is far from new, and is accepted in many studies on Cantonese (e.g. Matthews \& Yip I994; Yip I985) and Mandarin (e.g. Li \& Thompson I98I; McCawley I992). Furthermore, a number of other languages from diverse language families have been claimed to lack adjectives altogether: for example, Thai (Prasithrathsint 2000), and Lushootseed, and Cora (Beck I999). Again, such claims are accepted by many specialists in the relevant languages. However, as in the case of Cantonese, these languages typically exhibit distributional patterns that at least appear to distinguish a subclass of 'adjectival verbs' (Wetzer I996: 30-34). Schachter (I985) observes that the criteria for distinguishing major categories from subclasses are not always clear-cut, leaving some room for disagreement and uncertainty as to the correct analysis of a particular category system. For example, Paul (2003) argues on the basis of certain facts about nominal modification that a category of adjectives can be distinguished from verbs in Mandarin; however, she does not address the many similarities between (so-called) adjectives and verbs.

Precisely because of this uncertainty as to which distributional criteria are directly relevant to category membership, the idea that some languages lack adjectives remains a controversial one. In fact, both Baker (2003) and Croft (I99I, 200I) claim that, despite appearances to the contrary, adjectives are a universal category. For Baker (2003), adjectives are universal at the level of syntax, while for Croft (I99I, 200I), they are universal at the level of functional prototypes. We address each of these claims in turn.

\section{I Baker's universal theory of lexical categories}

We have assumed, following Culicover (I999) and Croft (200I), that categories are identified by language-specific criteria, and that there are no universal syntactic categories. According to this view, the fact that all languages seem to have nouns and verbs can be attributed universal facts about the nature of conceptual structure: all languages have some conventional way of distinguishing predicates from arguments. In opposition to this view, Baker (2003) provides extensive arguments in favour of universal syntactic categories. He proposes that all languages have a three-category system of nouns, verbs, and adjectives, where nouns are bearers of a referential index, verbs are licensors of specifiers, and adjectives are privatively defined as having neither of these syntactic properties. Importantly, Baker defines the 
syntactic categories at an abstract level of syntax, so that his analysis appears immune from the criticism that 'adjectives' in one language are identified by different distributional criteria than 'adjectives' in another language. If one accepts Baker's abstract conception of syntax, then the idea of universal categories at least becomes plausible. Here, we consider Baker's view of adjectives.

Because adjectives lack the ability to license their own subject, they must have the support of a functional category called Pred in order to act as predicates (Baker 2003: 34-46). One example Baker discusses at length is the case of Mohawk - a language widely believed to lack a category of adjectives distinct from verbs. Baker acknowledges that stative intransitive predicates with meanings like 'big' and 'white' behave like verbs in almost all respects. For example, they combine with tense and aspect morphemes, they do not need the support of a copular verb to act as predicates, and they must occur in a relative clause in order to act as nominal modifiers. However, he shows that stative intransitive verbs behave somewhat differently than other verbs with respect to their occurrence in a special attributive noun incorporation construction, and with respect to which aspect markers they combine with. He relates these facts to the proposal that adjectives lack the ability to license a specifier on their own. The fact that stative aspect marking is obligatory with adjectives, and that no other kind of aspect marking is allowed, is given as evidence that what, in Mohawk, looks like the stative aspect marker (transcribed as $-\Lambda$ ) is really functioning as Pred - the functional category that adjectives must combine with in order to act as predicates (2003: 257f.). Baker concludes that Mohawk has a lexical category of adjectives, but that adjective roots always combine with Pred to form stative verbs prior to lexical insertion. It is therefore only in very subtle ways that the distinctive properties of adjectives are apparent.

The evidence that Baker uses to argue for a category of adjectives appears to support his theoretical proposal, assuming a view of grammar permitting various abstract elements of syntactic structure. In response to the question of why adjectives are only allowed to surface in a couple of special contexts, Baker (2003: 253) proposes a parameter: 'in some languages, an $\mathrm{A}(\mathrm{P})$ must be in the minimal domain of Pred'. He argues that this parameter can explain the fact that attributive adjectives in Mohawk only occur with noun incorporation. Simple attributive constructions (without incorporation) are ruled out because the adjective cannot combine with Pred from within the NP unless extra functional structure, such as a relative clause, is present (Baker 2003: 258). However, when a noun is incorporated into the adjective, the noun-adjective unit can then combine with Pred to become its complement (where the specifier of Pred is a NP or an empty pro), receiving an attributive interpretation (Baker 2003: 26If.), as in (82) (where $\mathrm{MsS}=$ masculine singular subject, $\mathrm{NOML}=$ nominalizer, $\mathrm{STAT}=$ stative aspect, and $\mathrm{NE}=$ pronominal particle). 
(82)
Ra-ksa-ht-owan- $[\Lambda]$ ne Sak.
MsS-child-NOML-big-STAT NE Sak
'Sak is a big child.'

(Baker 2003: 262)

Baker does not, however, rule out the possibility that the special properties of 'adjectives' in Mohawk may be attributed to semantic requirements of the two constructions in which they occur. With reference to the examples that Baker (2003: 258-263) presents, it seems plausible that the attributive noun incorporation construction in Mohawk selects only non-dynamic, oneargument, verbs - i.e. a semantic class of verbs analogous (but not necessarily identical) to the class of verbs selected by the Cantonese comparative construction. Similarly, the obligatory stative aspect marking on this same class of verbs in Mohawk (Baker 2003: 257f.) may be analogous to 'default' intensification with houz in Cantonese (see section 2.2.2 above): a morpheme that is optional with some verbs obligatorily combines with verbs of a particular semantic type, losing its semantic effect in this context. The particular combination of formal and semantic properties in these constructions is conventional, and therefore not strictly predictable from either syntactic or semantic principles. Nevertheless, if this analysis is correct, the class of lexical items these constructions select is a semantic class of verbs rather than a syntactic category of adjectives. Consistently with the parallel-architecture theory we are assuming, this analysis does not require any abstract level of syntactic structure, and therefore maintains a notion of syntactic category based on (surface-level) phrase-structure configurations and/or inflectional morphology.

How might we distinguish Baker's analysis from our own proposal on empirical grounds? For Cantonese, we have already presented detailed evidence in section 3.2 above suggesting that the construction-specific categories that enter into adjective-like constructions are semantically based. Similar evidence would need to be presented for Mohawk, showing that all of the items that permit attributive noun incorporation and obligatory stative aspect marking belong to a particular semantic class. Another potential source of evidence is the presence or absence of adjective-verb synonyms. It is common in languages that have adjectives for some (near) synonyms to belong to different syntactic categories, as in the case of afraid (adj.) vs. fear (v.) in (83) or fond (adj.) vs. like in (84) (cf. Pustet 2000).

(83) (a) John is afraid of spiders.

(b) John fears spiders.

(adjective)

(verb)

(84)

(a) The boys are fond of Mary. (adjective)

(b) The boys like Mary.

(verb)

If adjectives are not present in a language, and if the relevant constructionspecific categories are semantically based, then it should be impossible for 
two words with the same semantic features to belong to different categories. The Cantonese data are consistent with this prediction (see in particular section 2.3, examples (5I) and (52)). Even among those predicate types most likely to result in adjective-verb synonyms, such as non-dynamic, twoargument predicates (McCawley I982; Pustet 2000), we find no synonymous adjective-verb pairs in Cantonese. There is no case, for example, in which two synonyms behave differently with respect to their occurrence in comparative constructions or A-A-deiz reduplication. If the same kind of analysis is applicable to Mohawk, we would similarly expect to find no adjective-verb synonyms whereby, for example, one member of the pair takes obligatory stative aspect marking but the other does not. Although the Mohawk data presented by Baker (2003: 258-263) appear to be consistent with this proposal, more examples would be needed to confirm these predictions. In any case, Baker fails to make a convincing case that all languages have a distinct syntactic category of adjectives. ${ }^{17}$

\subsection{Croft's theory of universal functional prototypes}

Croft's (I99I, 200I) proposal is in a similar spirit to Baker's: both agree that nouns, verbs, and adjectives are universal categories (in contrast to nonuniversal categories such as prepositions and complementizers). However, what they mean by this turns out to be rather different. According to Croft's (200I) theory of Radical Construction Grammar, individual languages do not have syntactic categories such as noun, verb, and adjective at all. Rather, what look like syntactic categories are actually construction-specific categories whose members overlap. If we were to apply the theory to Cantonese, there would be no primitive syntactic category of verbs, but several construction-specific categories (defined by negation with $m 4$, A-not-A question formation, aspect marking, etc.) whose members overlap to create the appearance of a single category. The categories of noun, verb, and adjective would exist, however, as universal categories defined in terms of functional prototypes. The prototypes are given in (85), adapted from Croft (I99I: 67):

\begin{tabular}{|c|c|c|c|}
\hline$(85)$ & SEMANTIC CLASS & PRAGMATIC FUNCTION & LEXICAL CATEGORY \\
\hline & Objects & Reference & Unmarked Nouns \\
\hline & Properties & Modification & Unmarked Adjectiv \\
\hline & Actions & Predication & Unmarked Verbs \\
\hline
\end{tabular}

These prototypes are claimed to predict certain patterns of markedness that are relevant for all languages, where markedness may be manifested in terms

[17] Pereltsvaig (200I) adopts the basic ideas of Baker's theoretical approach to lexical categories, but argues against the universality of the three-category system of nouns, verbs, and adjectives. She argues that Russian has two distinct adjective categories with similar thematic properties but different morphosyntactic properties. 
of overt coding (additional morphemes), limits on distributional possibilities, and/or infrequency of occurrence in actual language use. For example, property-denoting words used as predicates are predicted to show marked grammatical behaviour as compared with action-denoting words used as predicates, or at least similar behaviour. A language in which actiondenoting words used as predicates are MORE marked than property-denoting words used as predicates is predicted not to occur.

In English, for example, property-denoting words such as tall and white require the presence of a copular verb when used as predicates, whereas action-denoting words such as hit and cook do not. Conversely, propertydenoting words used as nominal modifiers are predicted to be less marked than action-denoting words used as nominal modifiers. Again, this appears to be correct for English: we can say the tall man, but not *the cook man; we must instead add extra morphemes: the man who cooks. If similar patterns occur in Cantonese, this would be evidence in favour of two distinct universal functional prototypes for adjectives and verbs.

In section 2, we identified a small class of non-verbal property words in Cantonese which might be labelled as 'adjectives'. These words do in fact support Croft's adjectival prototype: they freely occur in modification constructions, but they cannot be used as predicates. Thus, in terms of their distribution, they are unmarked with respect to modification and marked with respect to predication. Might the adjectival prototype also apply to those property words that we have classified as verbs? At first glance, this appears not to be the case. Action-denoting verbs and property-denoting verbs in Cantonese behave similarly to each other with respect to mainclause predication and nominal modification. Both occur in main predicate position without the support of a copular verb, a respect in which both classes of verbs are unmarked for predication (cf. section 2.I.I). In addition, both semantic classes of verbs typically occur with the morpheme ge 3 in the configuration [VP $g e \mathrm{~N}$ ] when modifying a noun, suggesting that both classes of verbs are marked with respect to modification (section 2.2.4). ${ }^{18}$

However, there are some subtle patterns that conform to the markedness patterns predicted by Croft's adjectival prototype. Gradable property verbs used as predicates in simple clauses require 'default intensification' with hou2, whereas action verbs do not (section 2.2.2). In this respect, property verbs may be considered more marked with respect to predication than action verbs. Conversely, property verbs (and other non-dynamic verbs) can occur without the morpheme gez in the $[\mathrm{V} \mathrm{N}]$ modification construction,

[18] Similar patterns are found in Thai. Prasithrathsint (2000: 260-267) shows that property verbs like dii 'good' behave similarly to action verbs in occurring in main predicate position without the support of a copula, and in allowing negation and imperative marking. In addition, both property verbs and action verbs must occur in relative clauses (either with or without a relative pronoun) when modifying a noun. 
whereas action verbs cannot (section 2.2.4). Thus, property verbs are apparently less marked with respect to nominal modification than action verbs. The patterns are similar in Mohawk, as described by Baker (2003: 249-263). Property verbs used as predicates require the presence of a stative aspect morpheme, whereas action verbs do not. Conversely, property verbs can be used as nominal modifiers in a special attributive noun incorporation construction, whereas action verbs cannot. We can conclude from this that despite the fact that most property-denoting words in Cantonese (and possibly also Mohawk) are verbs, the markedness patterns predicted by Croft's adjectival prototype are still applicable.

\section{Conclusion}

We have presented a multi-dimensional, feature-based analysis of grammatical and interpretive variation among members of the category 'verb' in Cantonese. While all verbs bear the syntactic category feature [V], there are other semantic and phonological features that affect the distribution of verbs independently of syntactic category. Constructions that resemble adjectival constructions in other languages license the semantic classes of verbs that are permanent, gradable, and/or non-dynamic, while constructions that resemble verbal constructions in other languages license the semantic classes of verbs that are dynamic, non-gradable, and/or non-permanent.

We have suggested that this kind of analysis may be applicable to other languages for which there is no clear distinction between verbs and adjectives, casting some doubt on Baker's (2003) claim that 'adjective' is a universally-instantiated syntactic category. Our analysis is, however, clearly compatible with Croft's (I99I, 200I) theory of typological markedness, which predicts that the functional prototype for adjectives may play a role in the markedness patterns of any language.

\section{REFERENCES}

Ansaldo, U. (1999). Comparative constructions in Sinitic: areal typology and patterns of grammaticalization. Ph.D. dissertation, Stockholm University.

Anward, J., Moravcsik, J. \& Stassen, L. (1997). Parts of speech: a challenge for typology. Linguistic Typology I. I67-I83.

Baker, M. C. (2003). Lexical categories: verbs, nouns, and adjectives. Cambridge: Cambridge University Press.

Beck, D. (1999). The typology of parts of speech systems: the markedness of adjectives. Ph.D. dissertation, University of Toronto.

Bhat, D. N. S. (1994). The adjectival category: criteria for differentiation and identification. Amsterdam: John Benjamins.

Bodomo, A. (2002). On the grammar of ideophones in Asian and African languages: the case of Dagaare and Cantonese. Paper presented at the Linguistic Society of Hong Kong Annual Research forum, Hong Kong University of Science and Technology.

Bolinger, D. (1967). Adjectives in English: attribution and predication. Lingua I8. I-34.

Bresnan, J. (1995). Category mismatches. In Akinlabi, A. (ed.), Theoretical approaches to African linguistics. Trenton, NJ: Africa World Press. 19-45. 


\section{E. J. FRANCIS \& S. MATTHEWS}

Carlson, G. (1977). Reference to kinds in English. Ph.D. dissertation, University of Massachusetts, Amherst.

Cheung, H.-N. S. (1994). A practical Chinese grammar. Hong Kong: Chinese University Press.

Chomsky, N. (1970). Remarks on nominalization. Studies on semantics in generative grammar. The Hague: Mouton de Gruyter. II-6I.

Chomsky, N. (198I). Lectures on government and binding. Dordrecht: Foris.

Chomsky, N. (1995). The Minimalist program. Cambridge, MA: MIT Press.

Croft, W. (199I). Syntactic categories and grammatical relations. Chicago: University of Chicago Press.

Croft, W. (200I). Radical Construction Grammar. Oxford: Oxford University Press.

Culicover, P. W. (1999). Syntactic nuts: hard cases, syntactic theory, and language acquisition. Oxford: Oxford University Press.

Déchaine, R.-M. (1993). Predicates across categories. Ph.D. dissertation, University of Massachusetts, Amherst.

Dixon, R. M. W. (1977). Where have all the adjectives gone? Studies in Language I. 19-80.

Francis, E. J. (1999). Variation within lexical categories. Ph.D. dissertation, University of Chicago.

Francis, E. J. \& Michaelis, L. A. (2003a). Mismatch: a crucible for linguistic theory. In Francis \& Michaelis (eds.), I-27.

Francis, E. J. \& Michaelis, L. A. (eds.) (2003b). Mismatch: form-function incongruity and the architecture of grammar. Stanford: CSLI Publications.

Goldberg, A. (1995). Constructions: a construction grammar approach to argument structure. Chicago: University of Chicago Press.

Gupta, A. (1980). The logic of common nouns. New Haven: Yale University Press.

Hengeveld, K. (1992). Non-verbal predication. Berlin: Mouton de Gruyter.

Hopper, P. J. \& Thompson, S. A. (1984). The discourse basis for lexical categories in universal grammar. Language 60. 703-752.

Jackendoff, R. S. (1977). X-bar syntax: a study of phrase structure. Cambridge, MA: MIT Press.

Jackendoff, R. S. (1997). The architecture of the language faculty. Cambridge, MA: MIT Press.

Jackendoff, R. S. (2002). Foundations of language. Oxford: Oxford University Press.

Kay, P. (2002). An informal sketch of a formal architecture for Construction Grammar. Grammars 5. I-I9.

Kay, P. \& Fillmore, C. J. (1999). Grammatical constructions and linguistic generalizations: the 'What's X doing Y' construction. Language 75. I-33.

Langacker, R. W. (I99I). Foundations of cognitive grammar (vol. 2). Stanford: Stanford University Press.

Lau, L. M. V. (1999). A study of Cantonese adjectives. M.Phil. dissertation, University of Hong Kong.

Li, C. \& Thompson, S. A. (198I). Mandarin Chinese: a functional reference grammar. Berkeley: University of California Press.

Malouf, R. P. (2000). Mixed categories in the hierarchical lexicon. Stanford: CSLI Publications.

Matthews, S. \& Yip, V. (1994). Cantonese: a comprehensive grammar. London: Routledge.

McCawley, J. D. (I982). The nonexistence of syntactic categories. In McCawley, J. D. (ed.), Thirty million theories of grammar. Chicago: University of Chicago Press. I76-203.

McCawley, J. D. (1992). Justifying part-of-speech assignments in Mandarin Chinese. Journal of Chinese Linguistics 20. 213-245.

Michaelis, L. A. (2003). Headless constructions and coercion by construction. In Francis \& Michaelis (eds.), 259-3I2.

Michaelis, L. A. (2004). Type shifting in Construction Grammar: an integrated approach to aspectual coercion. Cognitive Linguistics $\mathbf{1 5}$. I-67.

Mok, S.-S. (1998). Cantonese exceed comparatives. Ph.D. dissertation, University of California at San Diego.

Newmeyer, F. J. (1998). Language form and language function. Cambridge, MA: MIT Press.

Paul, W. (2003). Adjectival modification in Mandarin Chinese and related issues. Ms., Paris: Centre de Recherches Linguistiques Asie Orientale.

Pereltsvaig, A. (200I). Syntactic categories are neither primitive nor universal: evidence from short and long adjectives in Russian. In Franks, S., Gabrielle, L. \& Holloway King, T. (eds.), 


\section{THE CATEGORY 'VERB' IN CANTONESE}

Annual Workshop on Formal Approaches to Slavic Linguistics. Ann Arbor: Michigan Slavic Publishers. 209-227.

Pollard, C. \& Sag, I. A. (1994). Head-driven Phrase Structure Grammar. Chicago: University of Chicago Press.

Prasithrathsint, A. (2000). Adjectives as verbs in Thai. Linguistic Typology 4. 25I-27I.

Pustet, R. (2000). How arbitrary is lexical categorization? Verbs vs. adjectives. Linguistic Typology 4. I75-2I2.

Ross, C. (2002). Aspectual category shift. Journal of Chinese Linguistics 30. 343-369.

Sadock, J. M. (1990). Parts of speech in Autolexical Syntax. Proceedings of the Berkeley Linguistics Society I6. 269-28I.

Sadock, J. M. (199I). Autolexical Syntax: a theory of parallel grammatical representations. Chicago: University of Chicago Press.

Sadock, J. M. (2003). Mismatches in autonomous modular versus derivational grammars. In Francis \& Michaelis (eds.), 335-356.

Schachter, P. (1985). Parts-of-speech systems. In Shopen, T. (ed.), Language typology and syntactic description (vol. I). Cambridge: Cambridge University Press. 3-6I.

Shapiro, K. \& Caramazza, A. (2003). The representation of grammatical categories in the brain. TRENDS in Cognitive Science 7. 20I-206.

Smith, C. (1997). The parameter of aspect (2nd edn.). Dordrecht: Kluwer.

Stassen, L. (1997). Intransitive predication. Oxford: Clarendon Press.

Vogel, P. M. \& Comrie, B. (eds.) (2000). Approaches to the typology of word classes. Berlin: Mouton de Gruyter.

Wetzer, H. (1996). The typology of adjectival predication. Berlin: Mouton de Gruyter.

Yip, V. (1985). Is there a category 'adjective' in Cantonese? Ms., Brandeis University.

Yip, V. \& Matthews, S. (200I). Intermediate Cantonese: a grammar and workbook. London: Routledge.

Yuasa, E. (1998). Subordinate clauses in Japanese. Ph.D. dissertation, University of Chicago.

Yuasa, E. \& Francis, E. J. (2003). Categorial mismatch in a multi-modular theory of grammar. In Francis \& Michaelis (eds.), I79-229.

\section{Authors'addresses: (Francis)}

Department of English, Purdue University, 500 Oval Drive,

West Lafayette, IN 47907, U.S.A.

E-mail:efrancis@cla.purdue.edu

(Matthews)

Department of Linguistics, University of Hong Kong,

Pokfulam Road, Hong Kong, China.

E-mail:matthews@hkucc.hku.hk 